\title{
Simplified approach for locating the critical probabilistic slip surface in limit equilibrium analysis
}

\author{
Y. M. Cheng ${ }^{1}$, L. Li ${ }^{2}$, and L. L. Liu ${ }^{1}$ \\ ${ }^{1}$ Department of Civil and Environmental Engineering, Hong Kong Polytechnic University, Hong Kong SAR, China \\ ${ }^{2}$ School of Civil Engineering, Qingdao Technological University, Qingdao, China \\ Correspondence to: Y. M. Cheng (ceymchen@polyu.edu.hk)
}

Received: 16 January 2015 - Published in Nat. Hazards Earth Syst. Sci. Discuss.: 4 February 2015

Revised: 7 September 2015 - Accepted: 15 September 2015 - Published: 8 October 2015

\begin{abstract}
This paper aims to develop a rapid and practical procedure that can locate the slip surface for a slope with the minimum reliability index for limit equilibrium analysis at the minimum expense of time. The comparative study on the reliability indices from different sample numbers using the Monte Carlo simulation method has demonstrated that the results from a large enough sample number are related to those from a small sample number with high correlation indices. This observation has been tested for many homogeneous and heterogeneous slopes under various conditions in parametric studies. Based on this observation, the reliability index for a potential slip surface can be calculated with a small sample number, and the search for the minimum reliability index and the slip surface can be determined by a heuristic optimization algorithm. Based on the comparisons between the critical deterministic and probabilistic slip surfaces for many different cases, the use of the proposed fast method in locating the critical probabilistic slip surface is found to perform well, which is suitable for normal routine analysis and design works.
\end{abstract}

\section{Introduction}

It is widely accepted that slopes with safety factors greater than unity are not necessarily safe because of the underlying geotechnical variability and uncertainty, as well as the simplifications assumed when using predictive methods. Hong Kong is well known for slope failures, with an average of approximately 300 such failures per year. Billions of dollars are spent on slope analysis and stabilization each year in Hong Kong. It has been noted by the Hong Kong Government that approximately $5 \%$ of the stabilized slopes in
Hong Kong have eventually failed, and that many slopes with safety factors greater than 1.0 still ultimately fail (Hong Kong SAR Government, 2000). The assessment of slope stability and the reliability of the assessment have become an important topic in Hong Kong, China, Taiwan and many developed cities elsewhere where collapse of slopes may have disastrous effects on human lives and properties.

Although the use of a deterministic approach for calculating the minimum safety factor is useful for design and stabilization purposes, the reliability of the results is also an important issue for many practical problems. A probabilistic or reliability approach that can deal with the uncertainty and variability in the problem will be complementary to the classical safety factor evaluation. One of the reasons that the reliability has not commonly been determined in the past is the long computation time required in the analysis.

The conventional deterministic approach is based on minimizing the safety factor (FS for "factor of safety") over a range of potential slip surfaces, and the critical solution is called the critical deterministic slip surface (cdss) (Arai and Tagyo, 1985; Baker, 1980; Greco, 1996; Goh, 1999; Cheng, 2003; Bolton et al., 2003; Zolfaghari et al., 2005; Li et al., 2010, 2011; Cheng and Li, 2007; Cheng et al., 2008a, b). Based on the cdss, the failure probability and reliability index can be evaluated approximately, which is a relatively simple operation favoured by many engineers (Liu et al., 2015). There have been many attempts in recent years to use a probabilistic approach for analysing the safety of slopes. One common approach to determine the reliability of a slope is to assume it to be equal to the reliability index of the critical deterministic slip surface. Attempts to use this approach include Chowdhury et al. (1987), Honjo and Kuroda (1991), 
Christian et al., (1994) and many others. Another approach is to search for the slip surface with the minimum reliability index; this surface is known as the critical probabilistic slip surface (cpss) approach (e.g. Li and Lumb, 1987; Hassan and Wolf, 1999; Bhattacharya et al., 2003; Xue and Gavin, 2007). Several researchers have applied finite-element methods and random field theory to the probabilistic analysis of slopes. These methods considered the spatial variability that is inherent even in "homogeneous" slopes (Griffiths and Feton, 2004; Griffiths et al., 2009, 2011; Xu and Low, 2006). As mentioned by Cheng et al. (2007b), the use of finite-element methods is time-consuming in analysis with practical limitations in certain special cases. Finite-element analysis of slope stability is therefore still not favored by engineers for routine design work.

There are a number of approaches for probabilistic slope stability analysis that have differing assumptions, limitations and capabilities for handling problems with various levels of mathematical complexity. The approaches generally fall into one of two categories: (1) approximate methods - such as the first-order and second-order reliability method (FOSM, SORM) method, the improved point estimate method and the surrogate model methods - and (2) the Monte Carlo simulation method (MCSM). The former approach (approximate method) includes the works by Hasofer and Lind (1974), Li and Lumb (1987), Low et al. (1998), Low and Tang (2007), Oka and Wu (1990), Chowdhury and Xu (1995), Duncan (2000), El-Ramly et al. (2002), Hong and Roh (2008), Xue and Gavin (2007) and others. The surrogate method that includes the response surface method and kriging model (Yi et al., 2015; Zhang et al., 2013) can also provide a good estimation of the system reliability at reduced computation. The latter approach (MCSM) includes the works by Au and Beck (2001, 2003), Au et al. (2007, 2010), Ching et al. (2009) and others. The use of the MCSM can produce good results, although it can be computationally intensive, especially if the probability of failure is small. The FOSM and SOFM methods usually require the partial derivatives of the safety factor to be determinate, which may be not available for some slip surfaces. The widely used mean-value first-order second-moment method (MFOSM; Hassan and Wolff, 1999; Xue and Gavin, 2007) uses a finite-difference technique to form the gradient of the function. However, as discussed by Cheng et al. (2008c), because failure to converge during safety factor determination is common for slope stability analysis and is equivalent to the presence of discontinuities in the safety factor function, both finite-difference techniques and explicit partial derivatives in the first-order second-moment method encountered problems during use. Besides the above methods, there are also many other approximate methods to determine the system reliability of a slope (Zhang et al., 2011).

The classical assessment approach using a probabilistic slope analysis is usually computationally intensive, and there is a growing need for a more rapid assessment of the crit- ical probabilistic slip surface. This requirement is particularly important for many highway projects in which there are hundreds of sections to be considered. It is generally recognized that the search for the critical probabilistic slip surface is similar in principle to that for the minimum FS surface in the deterministic approach. Hassan and Wolff (1999) have proposed a method to search for the critical slip surface associated with the minimum reliability index obtained by the MFOSM. To reduce the amount of computation, Cho (2009) has adopted the Monte Carlo simulation method with approximated limit state functions based on the ANN (Artificial Neural Network) model, with results comparable to those based on FORM or SORM, while Kang et al. (2015) have adopted the Gaussian process regression with Latin hypercube sampling method. The method was developed based on their observation that the critical probabilistic slip surface generally coincides with that obtained by setting one dominant parameter (random variable) to a low value. When the cohesion of soil, the friction angle and the location of water table are important variables in the problem, this empirical approach is cumbersome and tedious to manipulate. This paper aims to provide a fast and simple approach to finding the critical probabilistic slip surface based on MCSM results. The proposed method only requires two calculations of the safety factors within each iterative search step. Although the authors cannot establish the theoretical basis for the proposed approach, the authors have experimented with thousands of cases and find that this approach can be effective and highly efficient such that risk analysis can be simple and practical for engineers.

\subsection{Limit state function}

The traditional definition of the limit state function or performance function as described in Eq. (1) is adopted this study:

$G(\boldsymbol{X})=\mathrm{FS}(\boldsymbol{X})-1$

where the vector $\boldsymbol{X}$ is input variables for the geotechnical properties (such as unit weight, internal friction angle, and cohesion). For the sake of simplicity, the safety factor FS is calculated using the simplified Bishop method for circular slip surfaces and the load factor method (using a special interslice force function $f(x)$ that is commonly adopted in China, and $x$ is a normalized horizontal distance in the range of 0 to 1.0) for non-circular slip surfaces (Cheng and Zhu, 2004). It should be noted that the proposed rapid assessment method is applicable to any specific stability analysis method.

\subsection{System reliability index with floating surfaces}

As mentioned above, the reliability index can be calculated either by the approximate methods or the MCSM. Griffiths and Fenton (2004) and Griffiths et al. (2009) have implemented the MCSM with a random field model for spatial 
distribution of shear strengths. The MCSM is adopted in the present study, due to its simplicity of use. The slope may fail along any potential slip surface; therefore, it is important to consider the slope stability problem in terms of a system of multiple potential slip surfaces. The procedure for using the MCSM to calculate the system reliability index (or, more directly, the probability of system failure) is straightforward. Let $Z$ denote all of the uncertain variables in the slope under consideration. Without loss of generality, it can be assumed that all the components of $Z$ are independent variables. In the case that a portion of the components of $Z$ are dependent variables, proper transformations as given by Ang and Tang (1984) can be applied to convert the problem into an independent input space. In this paper, $Z$ denotes the uncertain variables, while $\mathrm{z}$ denotes either the sample values or a certain fixed value of $Z$. The MCSM includes the following steps:

1. A counter denoted by $J_{\mathrm{s}}$ is initially set to 0 .

2. Generate $Z$ samples $\left(z_{i} ; i=1, \ldots, \mathrm{Ns}\right)$ from the assumed probability density function (PDF). For a probabilistic slope analysis, normal distribution and lognormal distributions are commonly assumed for the input variables in slope stability analysis, and Ns is total number of samples.

3. For each sample $z_{i}$, conduct a deterministic slope stability analysis to find the most critical slip surface among all the trial surfaces. If the safety factor for the most critical slip surface is less than 1 , the entire slope is considered to fail for that $z_{i}$ sample, and $J_{\mathrm{s}}=J_{\mathrm{s}}+1$.

4. Repeat step 3 for $i=1, \ldots$, Ns.

A simple estimate of the system failure probability of the slope can be defined as the ratio of $J_{\mathrm{s}}$ to Ns, and the relation between the failure probability and the reliability index is given by Duncan (2000). The MCSM procedure can be summarized mathematically by Eq. (2):

$P_{\mathrm{f}} \approx \frac{1}{\mathrm{Ns}} \sum_{i=1}^{\mathrm{Ns}} I\left[\operatorname{minFS}_{\omega}\left(z_{i}\right)<1\right]=P_{\mathrm{f}}^{\mathrm{MCSM}}$,

where $P_{\mathrm{f}}$ is failure probability of the slope as a system; $\omega$ is trial surface; $F_{\mathrm{s}_{\omega}}$ is the safety factor for that trial slip surface; $\min _{\omega} F_{\mathrm{S}_{\omega}}\left(z_{i}\right)$ is the safety factor for the critical slip surface; and $I[\times]$ is an indicator function. If $\min _{\omega} F_{\mathrm{s}_{\omega}}\left(z_{i}\right)<1$, $I\left[\min _{\omega} F_{\mathrm{s}_{\omega}}\left(z_{i}\right)<1\right]=1$; otherwise, it is equal to zero. The reliability index $\beta$ of a slope may be determined based on the assumed distribution function of the safety factor. The floating surfaces imply that the slip surfaces used to assess the performance of the slope for each sample $z_{i}$ are not identical, meaning that the reliability index $\beta$ is not available for a specific slip surface but belongs to the whole slope. However, based on the critical slip surface from a classical deterministic slope analysis, the reliability index for a given slip surface, as described below, may be applicable.

\section{Reliability index for specific slip surfaces}

Calculating the reliability index for a given slip surface by the MCSM may follow the following three steps:

1. Generate a trial slip surface (Cheng, 2003; Cheng and Li, 2007; Cheng et al., 2007b; Cheng et al., 2008a, b) that can be either circular or non-circular. Generate $Z$ samples $\left(z_{i} ; i=1, \ldots, \mathrm{Ns}\right)$ from the assumed PDF where Ns is the total number of samples. For a probabilistic analysis of slope, a normal distribution or a lognormal distribution is often assumed for the input variables.

2. For each sample $z_{i}$, a safety factor $F_{\mathrm{s} i}$ is obtained.

3. Repeat step 2 for $i=1, \ldots$, Ns.

Thus, Ns safety factors $F_{\mathrm{s} i}(i=1,2, \ldots, \mathrm{Ns})$ are obtained together with Ns performance function values $G_{1}, G_{2}, \ldots$, $G_{\mathrm{Ns}}$. The failure probability of this given trial slip surface and its corresponding reliability index $\beta$ can be calculated by Eqs. (3), (4) and (5):

$$
\begin{aligned}
& P_{\mathrm{f}}=\frac{\sum_{i=1}^{\mathrm{Ns}} I\left[G_{i}<0\right]}{\mathrm{Ns}}, \\
& \beta=\frac{\sqrt{N s-1} \cdot \sum_{i=1}^{\mathrm{Ns}} G_{i}}{\mathrm{Ns} \sqrt{\sum_{i=1}^{\mathrm{Ns}}\left(G_{i}-\frac{\sum_{i=1}^{\mathrm{Ns}} G_{i}}{\mathrm{Ns}}\right)^{2}} \text { (for normal distribution), }}
\end{aligned}
$$

$$
\left\{\begin{array}{l}
\beta=\frac{\lambda_{1}}{\lambda_{2}} \\
\lambda_{2}=\sqrt{\ln \left[1+\left(\frac{\mu_{\mathrm{FS}}}{\sigma_{\mathrm{FS}}}\right)^{2}\right]} \lambda_{1}=\ln \left(\mu_{\mathrm{FS}}\right)-0.5\left(\lambda_{2}\right)^{2}, \\
\text { (for log-normal distribution) }
\end{array}\right.
$$

where $\sigma$ and $\mu$ are mean and standard deviation, respectively. It should be noted that, even though the soil parameters may be governed by the normal or log-normal distribution, the factor of safety may not be truly governed by the normal or log-normal distribution. Nevertheless, based on thousand of tests in homogeneous and non-homogeneous slopes, the distribution of the factor of safety is found to be nicely described 
by the normal or log-normal distribution in most of the test cases. There are three main considerations in the application of the MCSM. The first consideration is to generate samples of the soil parameters that coincide with the assumed PDF, which may either be normally or log-normally distributed. The Monte Carlo sampling approach (or random sampling) is the common sampling approach, and uniformly distributed random variables are first generated and later transformed into a normal distribution or log-normal distribution (Chen, 2003); the transformations are given in Eqs. (8) and (10).

The second consideration is the determination of the value of Ns. It is widely accepted that the output of the MCSM is sensitive to the number of samples Ns. When Ns is large, the random samples generated for each input variable are also large, and the match between the CDF (cumulative density function) created by sampling and the original input CDF is better. Hence, the level of noise in the simulation diminishes and the output becomes more stable at the price of increasing computational time. The optimum number of iterations depends on the sizes of the uncertainties in the input parameters (case-dependent problem) and the correlations between the input variables and the output parameter being estimated. A practical way to optimize the simulation process is to repeat the simulation using the same seed value with an increasing number of iterations. A plot of the number of iterations $m$ against the probability of unsatisfactory performance can indicate the minimum number of iterations at which the probability value will stabilize.

The third consideration is the equivalent computational effort for the following two approaches. Assume $\mathrm{Nm}$ total trial slip surfaces for the deterministic critical search (Nm safety factors or Nm equivalent trial slip surfaces). In one approach, $\mathrm{Nm} \times \mathrm{Ns}$ safety factors are required to determine the system reliability index. In the other approach, for one trial slip surface, Ns safety factors are calculated to determine one reliability index, and $\mathrm{Nm}$ trial slip surfaces are required to find the critical probabilistic slip surface. The computation times required for the two approaches are thus approximately identical, and it appears that either approach can be accepted for the analysis.

It is noted that the evaluation of the system reliability index can be notably time-consuming because $\mathrm{Nm} \times \mathrm{Ns}$ evaluations are required, and both $\mathrm{Nm}$ and $\mathrm{Ns}$ are generally large numbers (of the order of thousands), if a high level of accuracy is required. A typical representation of the failure intensity against the number of simulations during the Monte Carlo simulation is shown in Fig. 1. It is noticed that, unless the number of trials is large enough (which is actually casedependent), the failure intensity will be a fluctuating function depending on the number of trials. In the initial study of the present problem, a computational time of 2 to several days was commonly required for a complete analysis using a fast computer (Intel i5 as the CPU); such computational time is excessive for routine engineering design work. Furthermore, for many highway projects, there may be hundreds

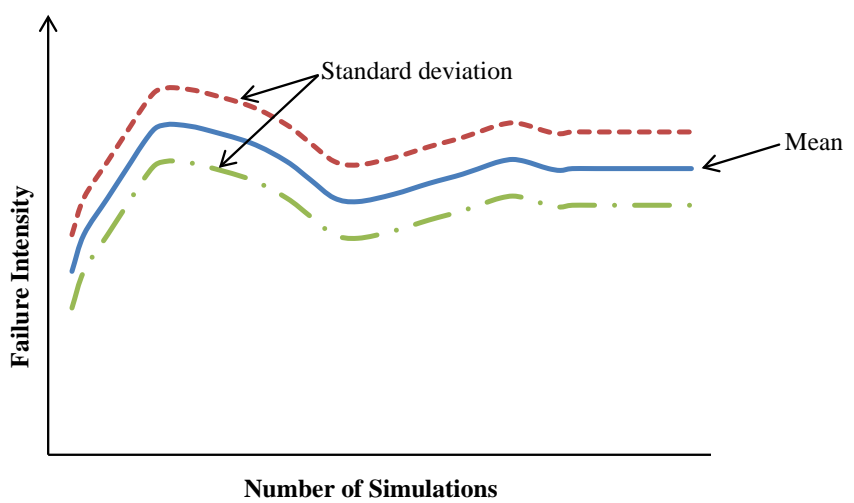

Figure 1. Typical relation between failure intensity and number of simulations in typical Monte Carlo simulation modelling.

of slopes to be considered. There is thus a need to develop a rapid search method for the critical probabilistic slip surface similar to the critical deterministic slip surface.

\section{Search for the critical probabilistic slip surface}

The critical deterministic slip surface for a slope is located by systematically generating a series of trial surfaces and analysing each slip surface with a set of soil parameters (Cheng, 2003; Cheng and Li, 2007; Cheng et al., 2007b, $2008 \mathrm{a}, \mathrm{b})$. In most of these algorithms, the location of the critical deterministic surface associated with the minimum safety factor, $F_{\mathrm{S}_{\min }}$, is formulated as an optimization problem, as follows:

$F_{\mathrm{S}_{\min }}=\operatorname{minFS}(p, x y)$,

where $p$ is the set of input geotechnical parameters $\left(c^{\prime}, \varphi^{\prime}\right.$, etc.); $x y$ is the set of co-ordinates defining the shape and location of the slip surface. The search for the critical probabilistic surface is similar to the determination of the critical deterministic surface. ( $\mathrm{Li}$ and Lumb, 1987). The critical probabilistic surface associated with the minimum reliability index $\beta_{\text {min }}$ is given by

$\beta_{\min }=\min \beta(p, x y)$,

where $\beta$ is the reliability index for a given set of geotechnical parameters (including the statistical properties) and a given geometry of the slip surface as defined by the coordinate parameters. An approach based on the MCSM is used to calculate the reliability index for trial slip surfaces in the critical probabilistic search. It has been noticed that the minimum reliability index $\beta_{\min }$ may not necessarily coincide with the critical deterministic slip surface, as will be demonstrated below. It has been assumed by many geotechnical engineers that locating the critical probabilistic slip surface may require considerable computational effort; this is true if a classical method is used to carry out the critical probabilistic search. 
Since the difference between $\beta_{\mathrm{FS}}$ (the reliability index of the critical deterministic slip surface) and $\beta_{\min }$ may be substantial, we generally cannot assume the critical deterministic slip surface to be the critical probabilistic slip surface. In view of this problem, the authors have carried out many studies with the MCSM, and based on many observations on the results, a fast approach is proposed for the evaluation of the reliability index. For normal problems, the fast approach has notably short computation times, and the accuracy of the result is sufficient for normal engineering use. In the case of a very critical section, the classical time-consuming approach is recommended because it will provide better accuracy albeit at the expense of time.

The actual procedures to search for the critical probabilistic slip surface using the harmony search method (other methods are also possible) are the following:

1. Generate a potential slip surface using the procedures given by Cheng (2003), Cheng and Li (2007), and Cheng et al. (2007b).

2. Calculate the reliability index for the potential slip surface by Eqs. (4) or (5).

3. Repeat steps 1 and 2 until several potential slip surfaces ( $M$ in this study) are obtained, and these $M$ potential slip surfaces are placed into harmony memory in the harmony search algorithm.

4. Initiate the parameters in the harmony search algorithm such as $H R$ (harmony memory consideration rate), $P R$ (pitch-adjusting rate), and the maximum iteration number $N t$ as the parameters for the harmony search algorithm.

5. Sort the $M$ potential slip surfaces in harmony memory by descending order of reliability index.

6. Generate a new potential slip surface using $H R$ and $P R$, calculate its reliability index, and compare it with that from the prior position in the harmony memory. If this surface is better than that from the prior position, replace the prior slip surface with the new potential slip surface, and the iteration number is increased by 1 .

7. Repeat step 5 and 6 until the maximum iteration number $N t$ is reached.

8. Output the first-order potential slip surface in the harmony memory as the optimum slip surface together with its reliability index as the minimum reliability index of the slope

Geem (2001) and Lee and Geem (2005) developed a harmony search meta-heuristic algorithm that was conceptualized using the musical process of searching for a perfect state of harmony. Musical performances seek to find pleasing harmony (a perfect state) as determined by an aesthetic standard, just as the optimization process seeks to find a global solution determined by an objective function. The harmony in music is analogous to the optimization solution vector, and the musician's improvisations are analogous to local and global search schemes in the optimization process. The SHM (Simple Harmony Method) uses a stochastic random search that is based on the harmony memory considering $H R$ and $P R$, and it is a population-based search method. This method is chosen by the authors, as Cheng et al. (2007b, 2008a) have demonstrated that this method is highly efficient for continuous global optimization problems and have implemented this procedure into commercial slope stability programs.

\section{Procedure for the MCSM}

The Monte Carlo sampling technique includes the following steps (Ang and Tang 1984):

1. For each random variable, generate Ns random numbers $\delta_{1}, \delta_{2}, \ldots, \delta_{\mathrm{Ns}}$, varying uniformly from 0 to 1 . For each pair of random numbers $\delta_{i}$ and $\delta_{i+1}$ from the list of random variables $\delta_{1}, \delta_{2}, \ldots, \delta_{\mathrm{Ns}}$, use Eq. (8) (Ang and Tang, 1984; Chen, 2003) to transform the random numbers $\delta_{1}$ and $\delta_{2}$ to normally distributed random numbers $\lambda_{i}$ and $\lambda_{i+1}$.

2. Next, generate random numbers $\eta_{i}$ and $\eta_{i+1}$ with normal distribution and independency using Eq. (9). $\eta_{i}, i=$ $1,2, \ldots$ Ns.

$$
\begin{aligned}
& \lambda_{i}=\left(-2 \ln \delta_{i}\right)^{0.5} \cos \left(2 \pi \delta_{i+1}\right), \\
& \lambda_{i+1}=\left(-2 \ln \delta_{i}\right)^{0.5} \sin \left(2 \pi \delta_{i+1}\right), \\
& \eta_{i}=\lambda_{i} \sigma_{i}+\mu_{i}, \\
& \eta_{i+1}=\lambda_{i+1} \sigma_{i}+\mu_{i},
\end{aligned}
$$

where $\sigma_{i}$ is the standard deviation of the random variable and $\mu_{i}$ is the mean value of the random variable.

3. The procedures will then continue from $i=1$ to Ns, and the original random number list $\delta_{1}, \delta_{2}, \ldots, \delta_{\mathrm{Ns}}$ will be transformed into a list of normally distributed random variables $\eta_{i}, i=1,2, \ldots$ Ns for which each variable is independent of the other variable. The random variables $\eta_{i}$ as given by Eq. (9) will be independent of each other and will follow the normal distribution, even though the original variable $\delta_{i}$ is randomly generated.

4. For variables $\delta_{i}$ following a log-normal distribution, let $y$ be the variables following a normal distribution; then $y_{i}=\ln \left(\delta_{i}\right)$ or $\delta_{i}=e^{y}$. The mean value $\sigma_{y}$ and the standard deviation $\mu_{y}$ of variable $y$ are then given by Eq. (10) as

$$
\begin{aligned}
& \sigma_{y}=\sqrt{\ln \left(1+V_{\delta}^{2}\right)}, \\
& \mu_{y}=\ln \left[\frac{\mu_{\delta}}{\sqrt{\left(1+V_{\delta}^{2}\right)}}\right] \text {, where } V_{\delta}=\frac{\sigma_{\delta}}{\mu_{\delta}} .
\end{aligned}
$$




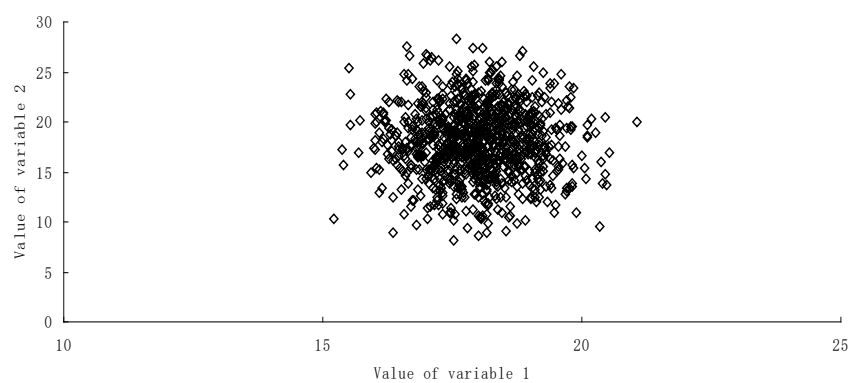

Figure 2. Sampling values of two independent variables with normal distribution.

$\delta_{i}$ can then be transformed into a normal distribution through variable $y$, and Eqs. (8) and (9) can be applied thereafter.

5. Take the unit weight $\gamma$ for example $\gamma_{i}=\lambda_{i} \sigma_{\gamma}+\mu_{\gamma}$, $\gamma_{i+1}=\lambda_{i+1} \sigma_{\gamma}+\mu_{\gamma}, i=1,2, \ldots$ Ns -1 . For each random variable, the procedures described above can be adopted, and the Ns sampling values for each random variable can be obtained as shown in Table 1 .

\section{Observations on the MCSM for two cases}

The authors have carried out many internal studies and have observed some interesting features which form the basis for the proposed rapid procedure. Before the discussion of the proposed rapid procedures, the observations will be illustrated by two examples. Based on the observations from these examples and many other examples not shown in the paper, it can be observed that a full MCSM may not be necessary for normal cases.

\subsection{Example 1}

The first problem example uses the work by Bhattacharya et al. (2003). The cross section of the slope is shown in Fig. 3, and the statistical geotechnical parameters are given in Table 2. In this example, four random variables are considered: the unit weight of soil $\left(\gamma, \mathrm{kN} \mathrm{m}^{-3}\right)$; the internal friction angle $\left(\varphi,{ }^{\circ}\right)$; the cohesion $(c, \mathrm{kPa})$; and the pore-water pressure coefficient $r_{\mathrm{u}}$, which is defined as the ratio of pore-water pressure to the unit weight per length. The independent random variables are assumed to be either normally distributed or log-normally distributed.

In Table $1, \mu_{\gamma}$ is the mean value of the unit weight, $\sigma_{\gamma}$ is the standard deviation of the unit weight, $\mu_{c}$ is the mean value of the cohesion, $\sigma_{c}$ is the standard deviation of the cohesion, $\mu_{\varphi}$ is the mean value of the internal friction angle, $\sigma_{\varphi}$ is the standard deviation of the internal friction angle, $\mu_{r_{\mathrm{u}}}$ is the mean value of the pore-water pressure coefficient, and $\sigma_{r_{\mathrm{u}}}$ is the standard deviation of the pore-water pressure coefficient.

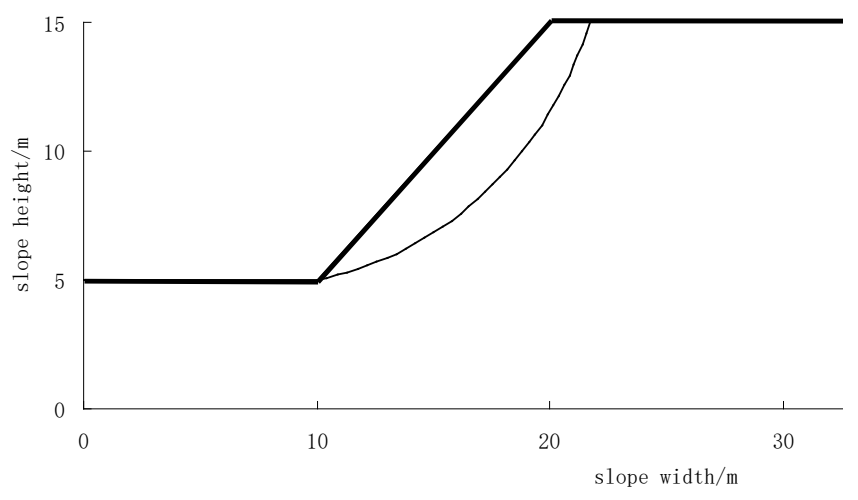

Figure 3. Cross section of the homogeneous slope in example 1.

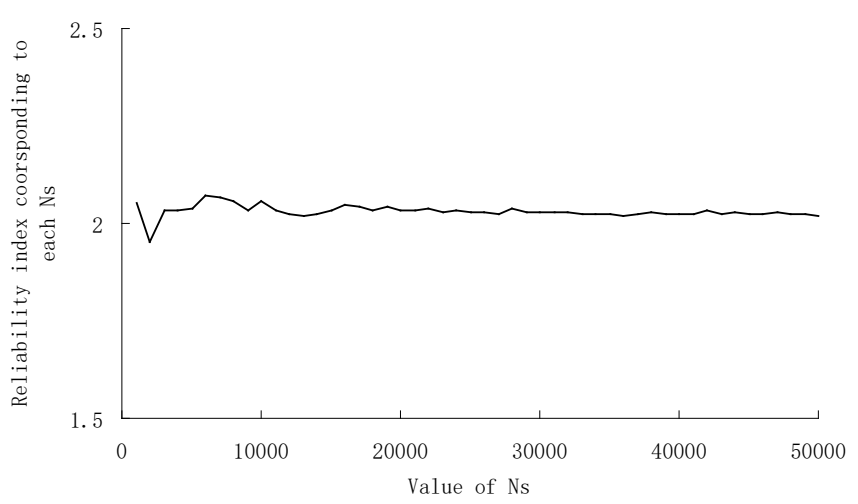

Figure 4. Numerical convergence of reliability index with different values of Ns.

Malkawi et al. (2000) noted that random seeds do not affect MCSM results and that sample sizes over 700 are sufficient for the MCSM to converge to the reliability index. A sample size of 700 may be adequate for some cases (casedependent), but this size is questionable for general conditions. It is more rational to expect that the value of the sample size (Ns in this paper) should depend on the reliability index of the trial slip surface or the system reliability index for the whole slope (Chen, 2003). Parametric studies are conducted for the problem in Fig. 3 to study the variation of results from the MCSM with various values of Ns, where the safety factor for each sampling trial is obtained by the simplified Bishop method. A series of values of Ns are assumed for this trial slip surface, and the results are given in Fig. 4; they are inconsistent with the general trend for normal MCSM. It is noticed from Fig.4 that there are fluctuation in the results with the change in Ns. When the value of Ns increases to 20000 , the reliability index tends to converge to a stable value of 2.02 . Using a sample size of 700 slightly overestimates the reliability index in this case.

The extensive computational effort required to apply the MCSM to the determination of a critical probabilistic slip surface is a primary reason that this approach has not been adopted by geotechnical engineers for routine analysis and 
Table 1. Sampling details for example 1.

\begin{tabular}{lllll}
\hline Sampling no. & $\gamma\left(\mathrm{kN} \mathrm{m}^{-3}\right)$ & $c(\mathrm{kPa})$ & $\varphi\left(^{\circ}\right)$ & $r_{\mathrm{u}}$ \\
\hline 1 & $\lambda_{1} \sigma_{\gamma}+\mu_{\gamma}$ & $\kappa_{1} \sigma_{c}+\mu_{c}$ & $\chi_{1} \sigma_{\varphi}+\mu_{\varphi}$ & $\xi_{1} \sigma_{r_{\mathrm{u}}}+\mu_{r_{\mathrm{u}}}$ \\
2 & $\lambda_{2} \sigma_{\gamma}+\mu_{\gamma}$ & $\kappa_{2} \sigma_{c}+\mu_{c}$ & $\chi_{2} \sigma_{\varphi}+\mu_{\varphi}$ & $\xi_{2} \sigma_{r_{\mathrm{u}}}+\mu_{r_{\mathrm{u}}}$ \\
3 & $\lambda_{3} \sigma_{\gamma}+\mu_{\gamma}$ & $\kappa_{3} \sigma_{c}+\mu_{c}$ & $\chi_{3} \sigma_{\varphi}+\mu_{\varphi}$ & $\xi_{3} \sigma_{r_{\mathrm{u}}}+\mu_{r_{\mathrm{u}}}$ \\
4 & $\lambda_{4} \sigma_{\gamma}+\mu_{\gamma}$ & $\kappa_{4} \sigma_{c}+\mu_{c}$ & $\chi_{4} \sigma_{\varphi}+\mu_{\varphi}$ & $\xi_{4} \sigma_{r_{\mathrm{u}}}+\mu_{r_{\mathrm{u}}}$ \\
5 & $\lambda_{5} \sigma_{\gamma}+\mu_{\gamma}$ & $\kappa_{5} \sigma_{c}+\mu_{c}$ & $\chi_{5} \sigma_{\varphi}+\mu_{\varphi}$ & $\xi_{5} \sigma_{r_{\mathrm{u}}}+\mu_{r_{\mathrm{u}}}$ \\
$i-1$ & $\lambda_{i-1} \sigma_{\gamma}+\mu_{\gamma}$ & $\kappa_{i-1} \sigma_{c}+\mu_{c}$ & $\chi_{i-1} \sigma_{\varphi}+\mu_{\varphi}$ & $\xi_{i-1} \sigma_{r_{\mathrm{u}}}+\mu_{r_{\mathrm{u}}}$ \\
$i$ & $\lambda_{i} \sigma_{\gamma}+\mu_{\gamma}$ & $\kappa_{i} \sigma_{c}+\mu_{c}$ & $\chi_{i} \sigma_{\varphi}+\mu_{\varphi}$ & $\xi_{i} \sigma_{r_{\mathrm{u}}}+\mu_{r_{\mathrm{u}}}$ \\
$\ldots$ & $\ldots$ & $\ldots$ & $\ldots$ & $\ldots$ \\
$\mathrm{Ns}$ & $\lambda_{\mathrm{Ns}} \sigma_{\gamma}+\mu_{\gamma}$ & $\kappa_{\mathrm{Ns}} \sigma_{c}+\mu_{c}$ & $\chi_{\mathrm{Ns}} \sigma_{\varphi}+\mu_{\varphi}$ & $\xi_{\mathrm{Ns}} \sigma_{r_{\mathrm{u}}}+\mu_{r_{\mathrm{u}}}$ \\
\hline
\end{tabular}

Where $\lambda_{i}, i=1,2, \ldots \mathrm{Ns}, \kappa_{i}, i=1,2, \ldots \mathrm{Ns}, \chi_{i}, i=1,2, \ldots \mathrm{Ns}$ and $\xi_{i}, i=1,2, \ldots \mathrm{Ns}$ are generated by Eq. (8). Considering the two random variables $\gamma$ and $c$ (variables 1 and 2 in Fig. 2), the sampling values using the Monte Carlo sampling technique are illustrated in Fig. 2.

Table 2. Mean values and standard deviations for soil property parameters.

\begin{tabular}{ccccccccc}
\hline Layer & \multicolumn{2}{c}{$\gamma\left(\mathrm{kN} \mathrm{m}^{-3}\right)$} & \multicolumn{2}{c}{$c(\mathrm{kPa})$} & \multicolumn{2}{c}{$\varphi\left(^{\circ}\right)$} & \multicolumn{2}{c}{$r_{\mathrm{u}}$} \\
\cline { 2 - 8 } & $\mu_{\gamma}$ & $\sigma_{\gamma}$ & $\mu_{c}$ & $\sigma_{c}$ & $\mu_{\varphi}$ & $\sigma_{\varphi}$ & $\mu_{r_{\mathrm{u}}}$ & $\sigma_{r_{\mathrm{u}}}$ \\
\hline 1 & 18.0 & 0.9 & 18.0 & 3.6 & 30.0 & 0.3 & 0.2 & 0.02 \\
\hline
\end{tabular}

design; this effort is also a reason why reliability assessment is not commonly performed in engineering practice. Most of the routine designs in Hong Kong require fast analysis not exceeding 1 to $2 \mathrm{~h}$ because there are too many sections to be considered. To overcome this limitation, decreasing the value of Ns would be an apparently simple solution. However, as shown in Fig. 4, the reliability index can be far from the stable value (2.02) if the value Ns is too small.

For the problem shown in Fig. 3, 100 trial circular slip surfaces are randomly generated in the analysis, and the $x$ and $y$ coordinates of the centres of the trial slip surfaces are shown in Fig. 5. If we assume Ns to be either 50000 or 2, the reliability index calculated when Ns $=50000$ can be taken as the "true" value, while the result calculated when Ns $=2$ is regarded as the "pseudo" reliability index. The true and pseudo reliability indices of the 100 randomly generated trial slip surfaces are calculated using the MCSM, and the scatter plots are shown in Figs. 6 and 7 (in which $y$ relates to the pseudo reliability indices, $x$ relates to the true reliability indices and $r$ is the correlation coefficient). It is noted from Fig. 7 that, even though the pseudo reliability indices are much larger than the true reliability indices, the true and pseudo reliability indices are highly correlated with a correlation coefficient of 0.9969 for normal distribution assumption and 0.9980 for log-normal distribution assumption. Similar results also apply to the more complicated load factor method (a Chinabased slope stability method which is popular in Asia; see Cheng and Lau, 2014) for both circular and non-circular slip surfaces with the correlation coefficients lying between 0.98

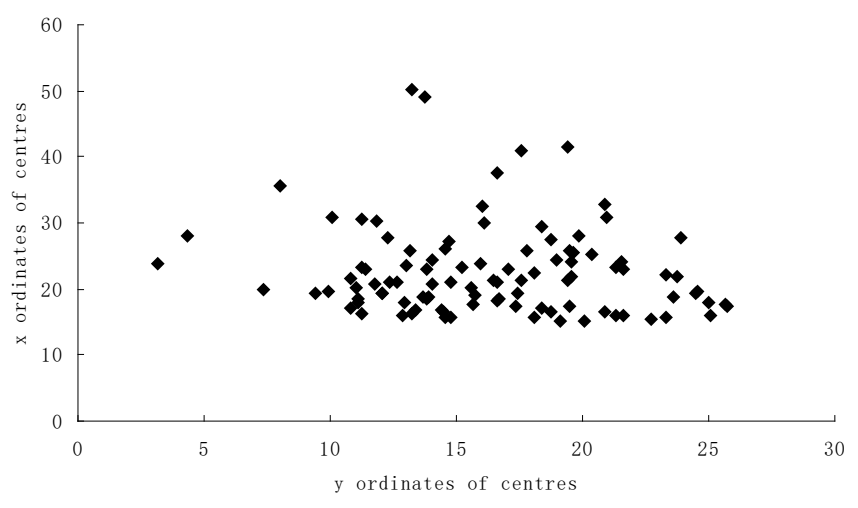

Figure 5. 100 centres of randomly generated trial slip surfaces.

to nearly 1.0, as are shown in Table 3 . The authors have tested several thousand cases, and virtually all the test cases have high correlation coefficients, except for several cases where the geometry is highly irregular with highly contrasting soil parameters that are typically not observed in real cases. The load factor method is considered in this paper, as this is a very popular method in Asia, and many slopes are designed according to this method. The method proposed in this paper is developed for fast practical application, and there are many actual applications of the present method in Asia.

\subsection{Example 2}

The observations as discussed above are subsequently tested for the case of heterogeneous slopes. Consider a second example that consists of a stratified clay slope bounded by a hard stratum below and parallel to the ground surface (shown in Fig. 8). The statistical geotechnical properties of the soils are given in Table 4. One hundred non-circular slip surfaces are randomly generated, with 14 slip surfaces being kinematically unacceptable; therefore, 86 total trial slip surfaces are adopted in this example. 
Table 3. Relations between pseudo reliability indices and true reliability indices.

\begin{tabular}{|c|c|c|}
\hline & $\begin{array}{l}\text { Relation between } \\
x \text { and } y\end{array}$ & $\begin{array}{l}\text { Correlation } \\
\text { coefficient } \\
r\end{array}$ \\
\hline $\begin{array}{l}100 \text { trial circular, normal distri- } \\
\text { bution, Bishop method }\end{array}$ & $y=2.8041 x^{1.6123}$ & 0.9969 \\
\hline $\begin{array}{l}100 \text { trial circular, log-normal } \\
\text { distribution, Bishop method }\end{array}$ & $y=3.0141 x^{1.4649}$ & 0.9980 \\
\hline $\begin{array}{l}100 \text { trial circular, normal } \\
\text { distribution, load distribution } \\
\text { method }\end{array}$ & $\begin{array}{l}y=3.1066 x^{1.53} \\
y=11.164 x-17.492\end{array}$ & $\begin{array}{l}0.9966 \\
0.9915\end{array}$ \\
\hline $\begin{array}{l}100 \text { trial circular, log-normal } \\
\text { distribution, load distribution } \\
\text { method }\end{array}$ & $\begin{array}{l}y=3.3492 x^{1.3967} \\
y=10.811 x-20.784\end{array}$ & $\begin{array}{l}0.9967 \\
0.9947\end{array}$ \\
\hline $\begin{array}{l}100 \text { trial non-circular, normal } \\
\text { distribution, load distribution } \\
\text { method }\end{array}$ & $\begin{array}{l}y=2.6768 x^{0.866} \\
y=2.6575 x-0.1962\end{array}$ & $\begin{array}{l}0.986 \\
0.982\end{array}$ \\
\hline $\begin{array}{ll}100 \text { trial non-circular, log- } \\
\text { normal distribution, } \\
\text { distribution method }\end{array}$ & $\begin{array}{l}y=2.5819 x^{1.016} \\
y=2.827 x-1.2396\end{array}$ & $\begin{array}{l}0.9945 \\
0.9911\end{array}$ \\
\hline
\end{tabular}

Table 4. Mean values and standard deviations for soil property parameters (soil number from top to bottom).

\begin{tabular}{lrrrr}
\hline \multirow{2}{*}{ Layers } & \multicolumn{2}{c}{$c(\mathrm{kPa})$} & \multicolumn{2}{c}{$\varphi\left(^{\circ}\right)$} \\
\cline { 2 - 5 } & $\mu_{c}$ & $\sigma_{c}$ & $\mu_{\varphi}$ & $\sigma_{\varphi}$ \\
\hline 1 & 38.31 & 7.662 & 0.0 & 0.0 \\
2 & 23.94 & 4.788 & 12.0 & 1.20 \\
\hline
\end{tabular}

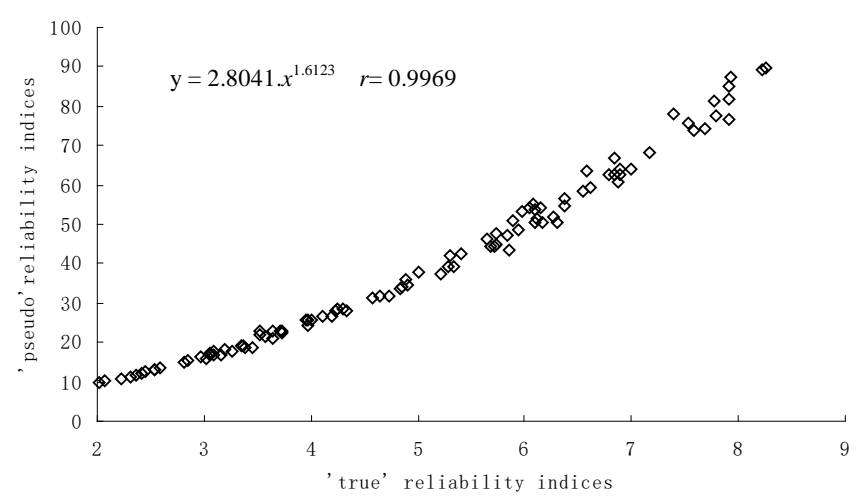

Figure 6. Relations between pseudo reliability indices and true reliability indices of 100 trial circular slip surfaces (normal distribution + Bishop method).

The load factor method is used to calculate the safety factors for the 86 non-circular slip surfaces, and the relations between the true reliability indices and the pseudo re-

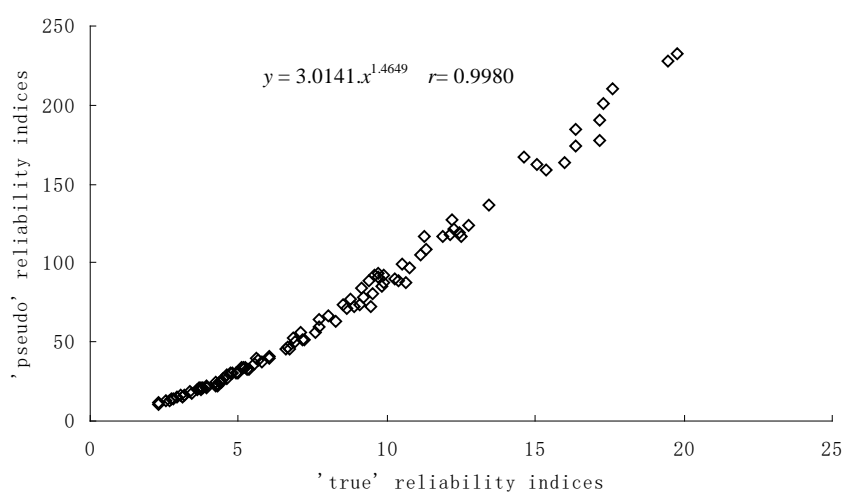

Figure 7. Relations between pseudo reliability indices and true reliability indices of 100 trial circular slip surfaces (log-normal distribution + Bishop method)

liability indices are given in Figs. 9 and 10 for the normal and log-normal distributions, respectively. Though the correlation coefficient for the normal distribution is lower than that for the homogeneous slope, the value is still 0.948. The observations about the correlation coefficients are therefore similar to those for the homogeneous slopes. The authors have also tested many other cases; in general, high correlation coefficients are obtained for many heterogeneous slopes, even though there is no theoretical background (at present) to model or describe this phenomenon. 
Table 5. Summary of reliability indices for the problem in Fig. 10.

\begin{tabular}{|c|c|c|c|c|c|c|c|c|}
\hline \multirow{3}{*}{$\begin{array}{l}\text { Shape of slip surface } \\
\text { and distribution type }\end{array}$} & \multicolumn{4}{|c|}{ Circular slip surface } & \multicolumn{4}{|c|}{$\begin{array}{l}\text { Non-circular slip surface } \\
\text { (load factor method) }\end{array}$} \\
\hline & \multicolumn{2}{|c|}{ cdss } & \multicolumn{2}{|c|}{ cpss } & \multirow[t]{2}{*}{ cdss } & \multirow[t]{2}{*}{ cpss } & \multirow{2}{*}{$\begin{array}{r}\text { Bhattacharya } \\
\text { (cdss) }\end{array}$} & \multirow{2}{*}{$\begin{array}{r}\text { Bhattacharya } \\
\text { (cpss) }\end{array}$} \\
\hline & $\begin{array}{l}\text { Load } \\
\text { factor }\end{array}$ & Bishop & $\begin{array}{l}\text { Load } \\
\text { factor }\end{array}$ & Bishop & & & & \\
\hline Normal distribution & 2.00 & 2.013 & 1.985 & 1.997 & 1.932 & 1.910 & 2.033 & 2.051 \\
\hline $\begin{array}{l}\text { Log-normal distribu- } \\
\text { tion }\end{array}$ & 2.25 & 2.261 & 2.233 & 2.240 & 2.147 & 2.120 & 2.303 & 2.311 \\
\hline
\end{tabular}

Note: cdss - critical deterministic slip surface; cpss - critical probabilistic slip surface.

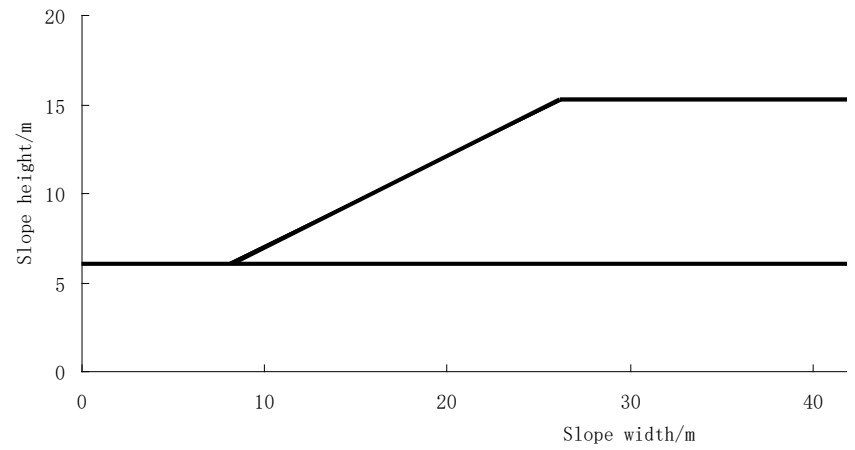

Figure 8. Cross section of the heterogeneous slope in example 2.

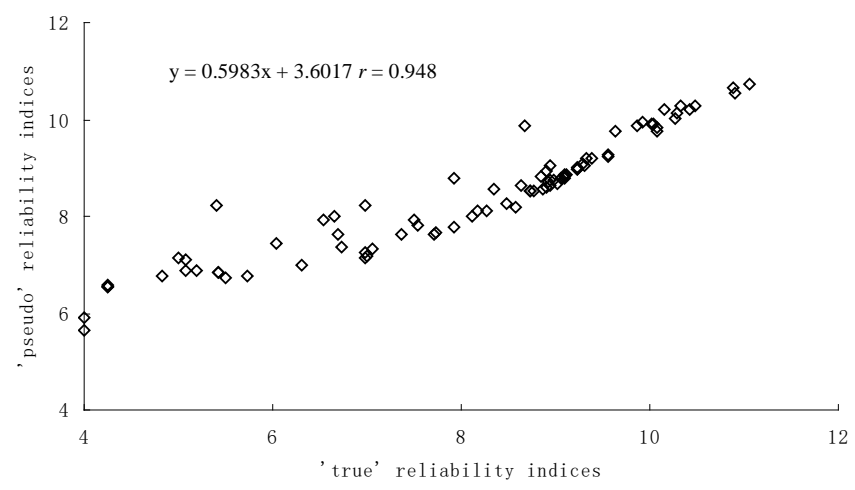

Figure 9. Relationship between pseudo reliability indices and true reliability indices of 86 non-circular trial slip surfaces (normal distribution + load factor method).

\section{Proposal for rapid analysis}

Based on the above observations concerning the MCSM results for many homogeneous and heterogeneous slopes with different geometries, the authors propose a rapid analysis approach as follows that should be sufficient for rapid engineering use. The pseudo reliability indices are used in the search

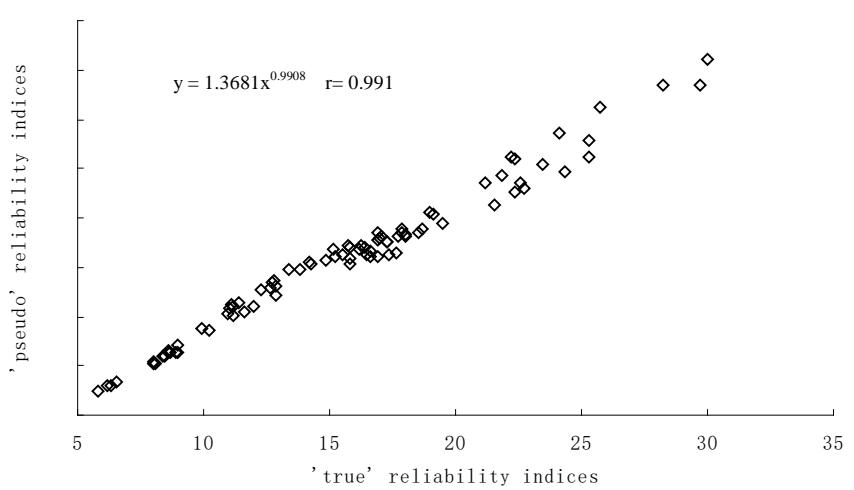

Figure 10. Relationship between pseudo reliability indices and true reliability indices of 86 non-circular trial slip surfaces (log-normal distribution + load factor method).

for the critical probabilistic slip surface; i.e. the optimization problem can be summarized as $\beta_{\min } \leftarrow \min \beta^{\mathrm{ps}}(p, x y)$, where $\beta^{\mathrm{ps}}$ represents the pseudo reliability index for the statistical properties of a given slip surface defined by its location parameters. The search for the critical probabilistic slip surface becomes as easy as that for the critical deterministic slip surface: the procedures are actually similar to that for the critical probabilistic slip by harmony search but with the following revisions.

1. Only two safety factors (or more but limited, as chosen by the users) are required within each iteration step, and the smaller reliability index is then computed.

2. Instead of factor of safety, put the reliability as the objective function in the minimization harmony search.

3. It should be noted that, at the end of the search, the true reliability index for the critical slip surface should be recalculated using the larger value of Ns.

An alternative approach is to obtain the true reliability index by the "correlation curve equation" if one is available. 


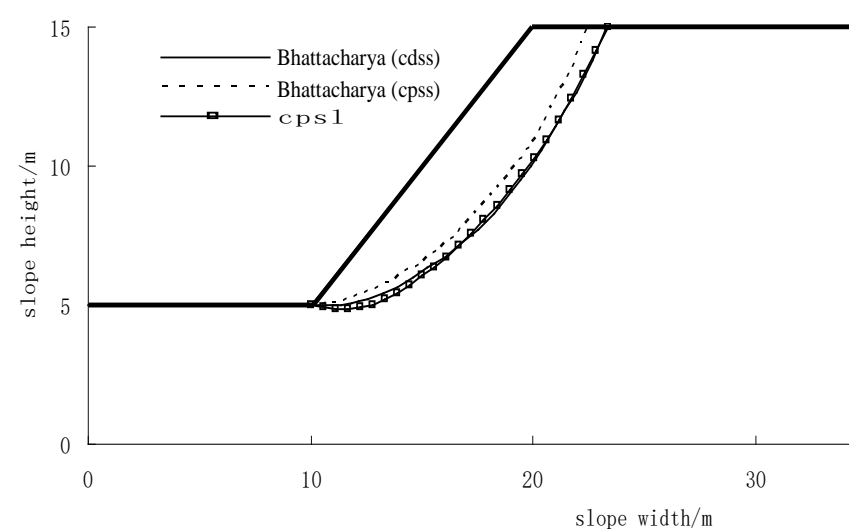

Figure 11. Summary of critical slip surfaces for example 1.

The present proposal can be viewed as another approximate method for the determination of the system reliability of a slope, which is suitable for routine design and analysis by the engineers. Even though the present proposal is not rigorous by nature, it is good enough for normal application and can perform better than using the cdss, which is commonly adopted for practical problems.

\subsection{Illustration of the results from rapid analysis using previous examples 1 and 2}

The proposed approach is then applied to the two abovementioned examples, and the results are compared with those from the literature. Consider the first example, where both circular and non-circular slip surfaces are considered using the simplified Bishop method and the load factor method to determine the safety factors. The results by Bhattacharya et al. (2003) with the critical deterministic slip surface and the critical probabilistic slip surface are given in Fig. 11. The results from the proposed approach and the results by Bhattacharya et al. (2003) are given in Table 5. It can be noted from Table 5 that all of the reliability indices for the critical deterministic slip surface are greater than those for the critical probabilistic slip surface. In addition, the reliability indices for the two references slip surfaces by Bhattacharya et al. (2003) are recalculated using the MCSM, and the results are all greater than those determined by the present study. It is clear that the results as given by Bhattacharya et al. (2003) are not the minimum reliability index of the critical probabilistic surface.

The results for the second example are summarized in Table 6 , as the unit weight is not given by Bhattacharya et al. (2003). In the present study, two combinations of unit weights for the two soil layers are assumed. In the first combination, a unit weight of $18.0 \mathrm{kN} \mathrm{m}^{-3}$ is assumed for both of the two layers of soil. For the second combination, a unit weight of $18.0 \mathrm{kN} \mathrm{m}^{-3}$ is assumed for layer 1 , and a unit weight of $48.0 \mathrm{kN} \mathrm{m}^{-3}$ is assumed for layer 2 . The critical deterministic slip surface and the critical probabilistic slip

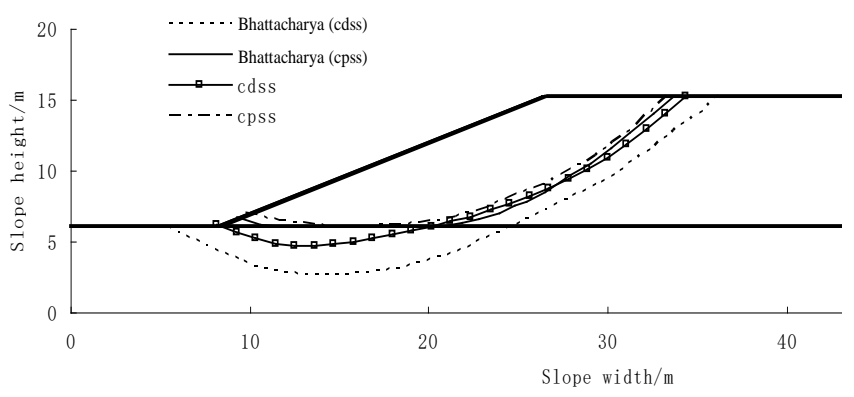

Figure 12. Summary of critical slip surfaces for example 2.

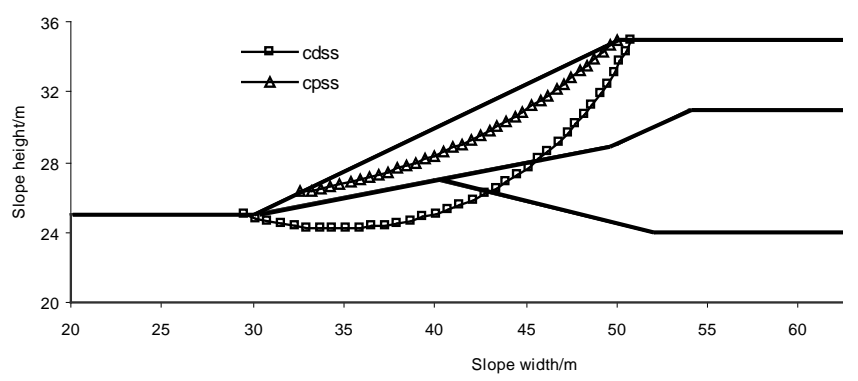

Figure 13. Cross section of the heterogeneous slope in example 3.

surface as given by Bhattacharya et al. (2003) are shown in Fig. 12. The reliability indices of these two slip surfaces are recalculated using the MCSM for different combinations of unit weights and for different distribution types. It is noted that there are differences in the location of the slip surface based on the reliability indices. For the critical deterministic slip surface ("cdss"), the reliability index is much larger than that for the "cpss" with the same parameters. From this result, it is clear that the adoption of the critical deterministic slip surface to determine the reliability index may not be generally acceptable.

\subsection{Illustration of the results from rapid analysis using example 3}

The third example is a three-layer slope with a cross section, as given in Fig. 13, while the geotechnical statistical parameters are given in Table 7.

The critical deterministic slip surface is given in Fig. 13, while the corresponding safety factor is 1.392 by the simplified Bishop method. The reliability indices for the critical deterministic slip surface are 3.281 and 3.802 for the normal distribution and log-normal distribution assumptions, respectively. The critical probabilistic slip surface is located only within the first layer, and the minimum reliability indices are 1.918 and 2.264, corresponding to the normal and log-normal distribution assumptions, respectively. The considerable difference in the location of the critical deterministic slip surface and the critical probabilistic slip surface, as well as the reliability indices, is clearly noted in this third example. Us- 
Table 6. Summary of reliability indices for the problem in Fig. 11 (soil number from top to bottom).

\begin{tabular}{l|l|lrrr}
\hline Shape of slip surface and distribution type & \multicolumn{4}{|c}{ Non-circular slip surface (load factor method) } \\
\hline & cdss & cpss & $\begin{array}{r}\text { Bhattacharya } \\
\text { (cpss) }\end{array}$ & $\begin{array}{r}\text { Bhattacharya } \\
\text { (cdss) }\end{array}$ \\
\hline $\begin{array}{l}\text { Both unit weight of } \\
18.0 \mathrm{kN} \mathrm{m}^{-3}\end{array}$ & $\begin{array}{l}\text { Normal } \\
\text { distribution }\end{array}$ & 3.840 & 2.408 & 3.897 & 4.089 \\
\cline { 2 - 6 } & $\begin{array}{l}\text { Log-normal } \\
\text { distribution }\end{array}$ & 4.770 & 3.230 & 5.422 & 5.235 \\
\hline $\begin{array}{l}\text { One is } 18 \mathrm{kN} \mathrm{m}^{-3} \\
\text { and the other is } 48.0 \\
\mathrm{kN} \mathrm{m}^{-3}\end{array}$ & $\begin{array}{l}\text { Normal } \\
\text { distribution }\end{array}$ & 3.707 & 2.393 & 3.897 & 5.639 \\
& $\begin{array}{l}\text { Log-normal } \\
\text { distribution }\end{array}$ & 4.906 & 3.200 & 5.422 & 7.884 \\
\hline
\end{tabular}

Table 7. Mean values and standard deviations for soil property parameters (soil number from top to bottom).

\begin{tabular}{lrrrrr}
\hline Layers & $\gamma\left(\mathrm{kN} \mathrm{m}^{-3}\right)$ & \multicolumn{2}{c}{$c(\mathrm{kPa})$} & \multicolumn{2}{c}{$\varphi\left({ }^{\circ}\right)$} \\
& & $\mu_{c}$ & $\sigma_{c}$ & $\mu_{\varphi}$ & $\sigma_{\varphi}$ \\
\hline 1 & 19.5 & 0.0 & 0.0 & 38.0 & 5.71 \\
2 & 19.5 & 5.3 & 0.7 & 23.0 & 2.86 \\
3 & 19.5 & 7.2 & 0.2 & 20.0 & 2.86
\end{tabular}

Table 8. Summary of reliability indices for example 3 in Fig. 13.

\begin{tabular}{lcr}
\hline $\begin{array}{l}\text { Shape of slip surface } \\
\text { and distribution type }\end{array}$ & \multicolumn{2}{c}{$\begin{array}{c}\text { Circular slip surface } \\
\text { (simplified Bishop method) }\end{array}$} \\
\cline { 2 - 3 } & cdss & cpss \\
\hline Normal distribution & 3.281 & 1.918 \\
Log-normal distribution & 3.802 & 2.264 \\
\hline
\end{tabular}

ing the critical deterministic slip surface as the critical probabilistic slip surface may be acceptable in certain cases, but it may also leads to a large error in other cases, and great care should be taken concerning this problem. A summary of the reliability indices are given in Table 8 .

\subsection{Illustration of the results from rapid analysis using example 4}

The fourth example is considered by Zolfaghari et al. (2005). The cross section of the slope is given in Fig. 14, and the statistical parameters are given in Table 9.

It can be seen from Fig. 14 that the left ends of the critical deterministic slip surface and the critical probabilistic slip surface are practically identical, but considerable differences can be found at the middle and the right exit ends of the slip surfaces. The results from the rapid method, as proposed in this paper, are actually better than those given by Zolfaghari
Table 9. Mean values and standard deviations for soil property parameters (soil number from top to bottom).

\begin{tabular}{lcrrrrr}
\hline \multirow{2}{*}{ Layers } & \multicolumn{2}{c}{$\gamma\left(\mathrm{kN} \mathrm{m}^{-3}\right)$} & \multicolumn{2}{c}{$c(\mathrm{kPa})$} & \multicolumn{2}{c}{$\varphi\left({ }^{\circ}\right)$} \\
& $\mu_{\gamma}$ & $\sigma_{\gamma}$ & $\mu_{c}$ & $\sigma_{c}$ & $\mu_{\varphi}$ & $\sigma_{\varphi}$ \\
\hline 1 & 19.0 & 0.9 & 15.00 & 1.5 & 20.0 & 2.0 \\
2 & 19.0 & 0.9 & 17.00 & 3.4 & 21.0 & 1.9 \\
& 19.0 & 0.9 & 5.00 & 0.5 & 10.0 & 0.6 \\
& 19.0 & 0.9 & 35.00 & 7.0 & 28.0 & 2.8 \\
\hline
\end{tabular}

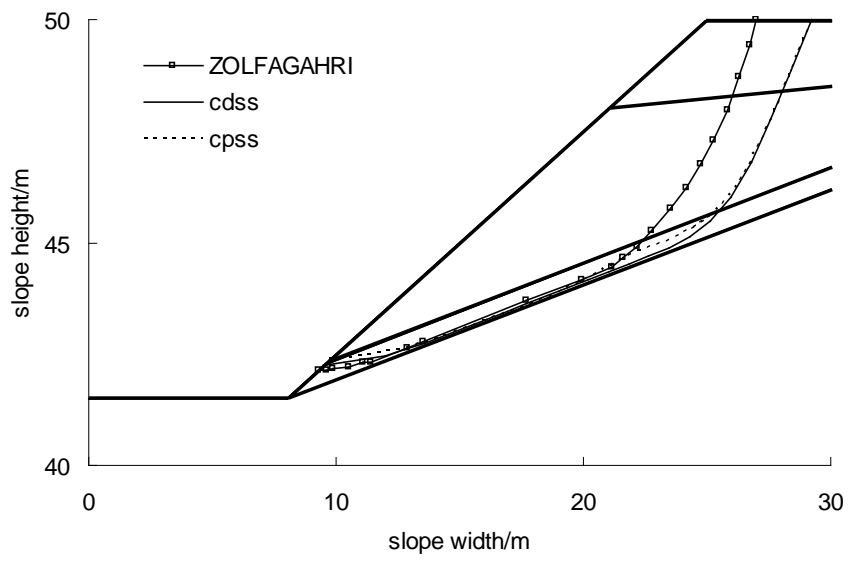

Figure 14. Cross section of Zolfaghari slope in example 4.

et al. (2005), which is further support for the application of the fast method for routine analysis and design.

\subsection{Illustration of the results from rapid analysis using example 5}

A further example in which vertical surcharge is applied is given for the problem in Fig. 15, while the soil parameters are given in Table 11. The analyses are carried out for the 


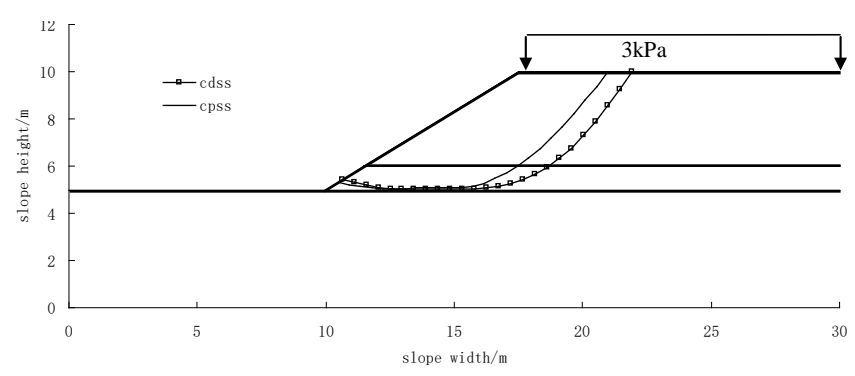

Figure 15. A problem with three soils and vertical pressure for noncircular slip surface analysis.

Table 10. Summary of reliability indices for the problem in Fig. 14.

\begin{tabular}{lrrr}
\hline $\begin{array}{l}\text { Shape of slip surface } \\
\text { and distribution type }\end{array}$ & \multicolumn{2}{c}{$\begin{array}{c}\text { Non-circular slip surface } \\
\text { (load factor method) }\end{array}$} \\
\cline { 2 - 4 } & cdss & cpss & Zolfaghari \\
\hline Normal distribution & 2.46 & 2.41 & 2.79 \\
Log-normal distribution & 2.60 & 2.55 & 3.02 \\
\hline
\end{tabular}

cases of circular and non-circular slip surfaces. This case is special in that the soil cohesion is notably low for soil layer 2, which creates a special slip surface and increases the difficulty of the optimization search. From the results as shown in Table 12, the reliability indices for cpss are always lower than those from cdss, which is similar to the above cases, and the differences are more pronounced for non-circular slip surfaces.

\section{Discussion}

For Hong Kong and other such places that are well known for frequent slope failures, where the slopes are composed of three to four layers of soils with varying soil parameters, the classical approach in evaluating the critical deterministic slip surface and determining the reliability index based on this slip surface is commonly practiced. A full analysis for the true reliability index using the full Monte Carlo simulation method is seldom applied, due to the excessive time requirement for the analysis. While this approach may be acceptable in some cases, the authors, as well as other researchers, have commented that there are many cases where the critical deterministic slip surface may not provide the critical reliability index. To attempt to solve this problem, the authors have constructed thousands of test problems with arbitrary geometry and soil parameters for a reliability study of slope based on this study.

By nature, slope stability analysis is a non-linear problem for the soil parameters. The reliability index based on cdss is hence not necessarily the true minimum reliability index. Based on the results from the MCSM for both homogeneous and heterogeneous slopes (thousands of internal studies but
Table 11. Mean values and standard deviations for soil property parameters (soil number from top to bottom).

\begin{tabular}{lrrrrr}
\hline Layers & $\gamma\left(\mathrm{kN} \mathrm{m}^{-3}\right)$ & \multicolumn{2}{c}{$c(\mathrm{kPa})$} & \multicolumn{2}{c}{$\varphi\left(^{\circ}\right)$} \\
\cline { 3 - 6 } & & $\mu_{c}$ & $\sigma_{c}$ & $\mu_{\varphi}$ & $\sigma_{\varphi}$ \\
\hline 1 & 11.0 & 20.0 & 2.0 & 5.0 & 0.0 \\
2 & 11.0 & 2.0 & 0.0 & 5.0 & 0.0 \\
3 & 11.0 & 25.0 & 0.0 & 5.0 & 0.0 \\
\hline
\end{tabular}

Table 12. Summary of reliability indices for the problem in Fig. 15.

\begin{tabular}{llc}
\hline $\begin{array}{l}\text { Shape of slip surface } \\
\text { and distribution type }\end{array}$ & \multicolumn{2}{c}{$\begin{array}{c}\text { Circular slip surface } \\
\text { (simplified Bishop method) }\end{array}$} \\
\cline { 2 - 3 } & cdss & cpss \\
\hline Normal distribution & 3.75 & 3.73 \\
Log-normal distribution & 4.36 & 4.35 \\
\hline Shape of slip surface & \multicolumn{2}{c}{ Non-circular slip surface } \\
and distribution type & \multicolumn{2}{c}{ (load factor method) } \\
\cline { 2 - 3 } & \multicolumn{2}{c}{ cdss } \\
\hline Normal distribution & 3.913 & cpss \\
Log-normal distribution & 4.514 & 4.622 \\
\hline
\end{tabular}

not shown in the present paper), an interesting phenomenon is observed, and a rapid approach in reliability analysis is proposed. The main advantage of the proposed fast approach is that two safety factor calculations (or more if needed) are required within each iteration step during the search for the critical probabilistic slip surface in the present paper. Though the reliability index for the critical probabilistic slip surface does not fully represent the reliability of the slope as a system, the critical probabilistic slip surface and the reliability index are still useful to many geotechnical engineers for the assessment. The proposed method is applicable to any specific stability analysis method, and the Bishop and load factor methods are adopted simply because of their simplicity and popularity in Asia. Based on the present results for several examples, as well as other results from internal studies, it is found that there is a high correlation between the pseudo reliability indices and the true reliability indices for different conditions. Although the pseudo reliability index for a given slip surface is greatly different from the true reliability index, the correlation coefficient between the pseudo and true series of values is greater than 0.9 (usually greater than 0.95 ) for all of the cases that have been tested by the authors, as well as many other cases not shown in this paper. This result is the basis for the rapid search approach proposed in this study. For those problems with a correlation less than 0.95 but greater than 0.9 , they are usually problems with highly contrasting soil parameters that may not be found for real cases. There are only a few test cases with a correlation less than 0.9 in 
the experience of the authors, which supports the use of the fast method as a practical tool for engineers in routine analysis and design work. If the engineers intend to obtain better results, the improvement in the result can be achieved by using more safety factor calculations within each iteration step (Ns $>2$ ) during the search for the critical probabilistic slip surface, and the computer code that the authors have developed have allowed for this requirement. For normal engineering works where very high accuracy may not be required, however, the use of two computations is adequate in general.

The authors have performed several thousands of tests in homogeneous and non-homogeneous slopes, and the performance of the fast method is actually good in nearly all cases. It is noticed that in most cases the fast method will give similar or smaller reliability indices as compared with cdss with only few exceptions. In actual application, the fast method is applied while the reliability index for cdss is also suggested to be evaluated as a counter-check for routine analysis and design. Determination of the reliability indices from the cdss and fast method approaches are very fast in operation (usually within $20 \mathrm{~min}$ ) as compared with the full Monte Carlo simulation (may require 1 day of computation). The results from cdss or the fast method can be useful to the engineers in their works, particularly when there are a significant amount of construction works being undertaken in Asia.

The present fast approach can be incorporated into many research and commercial codes easily with minor effort, and a good approximation of the reliability index for a given problem can be determined within minutes, which is suitable for normal engineering use. At present, reliability analysis is not commonly considered for routine slope design work because of the long computation time, and it is suggested to adopt the present rapid approach that can provide an acceptable solution within an acceptable time period suitable for routine engineering analysis and design work. In fact, the fast method has already been used with satisfaction by some engineers for normal engineering works in Hong Kong.

\section{Conclusions}

Classically, cdss is used by the engineers for simplicity, while the full MCSM analysis is seldom performed, due to the lengthy computation required. In this paper, cdss is demonstrated to be a poor assessment of the reliability index of slope for certain cases from five examples (many more in the internal studies). Even though the proposed fast method for cpss, as suggested in the present paper, is based on the observations of many test problems without any theoretical background, the authors have carried out thousands of trial tests to confirm the applicability, and the results have supported this method for limit equilibrium analysis. For the full MCSM results, the analysis must be calculated with extensive computational effort that may require 1 or more days of computations, while the fast method requires less than half an hour for the analysis. For highly important cases or complicated problems, the full MCSM is still recommended. Conversely, the rapid approach, as proposed in the present study, is targeted toward the majority of slopes requiring routine analysis and design, and the test results, as given in the present study, support the adoption of the proposed rapid method for normal routine engineering work with a significant savings in computational time. 


\section{Appendix A}

Table A1. List of symbols.

\begin{tabular}{ll}
\hline$G(\boldsymbol{X})$ & Performance function, $\boldsymbol{X}$ is input parameters vector \\
$\mathrm{FS}(\boldsymbol{X})$ & Factor of safety function \\
$f(x)$ & Interslice force function, and $x$ is a normalized distance from 0 to 1.0 \\
$Z$ & Samples of variables \\
$\mathrm{PDF}$ & Probability density function \\
$\mathrm{Ns}$ & Total number of samples \\
$P_{f}$ & Failure probability \\
$\omega$ & Trial failure surface \\
$\beta$ & Reliability index \\
$\mu$ & Mean values of variables \\
$\sigma$ & SD of the variables \\
$N \mathrm{~m}$ & Number of trials for deterministic search \\
$p$ & The set of input geotechnical parameters $\left(c^{\prime}, \varphi^{\prime}\right.$, etc. $)$ \\
$c^{\prime}$ & Soil cohesive strength \\
$\varphi^{\prime}$ & Soil friction angle \\
$\gamma$ & Unit weight of soil \\
$r_{u}$ & Pore-pressure ratio \\
$x y$ & Coordinates of trial failure surface \\
$\mathrm{Hr}$ & Harmony memory consideration rate \\
$\mathrm{Pr}$ & Pitch adjusting rate \\
$\mathrm{Nt}$ & Maximum number of iteration in harmony search \\
$\delta_{i}$ & Random variables, which may be either normally distributed or log-normally distributed \\
$\eta_{i}$ & Normal distributed random variables for which each variable is independent of the others \\
\hline
\end{tabular}


Acknowledgements. The present work is supported by the Research Grants Council of the Hong Kong SAR Government through the project PolyU 5128/13E, as well as the National Natural Science Foundation of China (grant no. 51008167), the S\&T Plan Project (grant no. J10LE07) from the Shandong Provincial Education Department and the Research Fund for the Doctoral Program of Higher Education of China (grant no. 20103721120001).

Edited by: P. Tarolli

Reviewed by: F. Kang and two anonymous referees

\section{References}

Ang, A. H. and Tang, W.: Probability concepts in engineering planning and design, vol. 2, John Wiley and Sons Inc, New York, 1984.

Arai, K. and Tagyo, K.: Determination of noncircular slip surfaces giving the minimum factor of safety in slope stability analysis, Soil. Found., 21, 43-51, 1985.

$\mathrm{Au}, \mathrm{S}$. K. and Beck, J. L.: Estimation of small failure probabilities in high dimensions by subset simulation, Probabilist. Eng. Mech., 16, 263-277, 2001.

Au, S. K. and Beck, J. L.: Subset simulation and its application to seismic risk based on dynamic analysis, J. Engin. Mech., 129, 901-917, 2003.

Au, S. K., Ching, J., and Beck, J. L.: Application of subset simulation methods to reliability benchmark problems, Struct. Saf., 29, 183-193, 2007.

Au, S. K., Cao, Z. J., and Wang, Y.: Implementing advanced Monte Carlo simulation under spreadsheet environment, Struct. Saf., 32, 281-292, 2010.

Baker, R.: Determination of the critical slip surface in slope stability computations, Int. J. Numer. Anal. Meth. Geomechan., 4, 333359,1980 .

Bhattacharya, G., Jana, D., Ojha, S., and Chakraborty, S.: Direct search for minimum reliability index of earth slopes, Comput. Geotechn., 30, 445-462, 2003.

Bolton, H. P. J., Heymann, G., and Groenwold, A.: Global search for critical failure surface in slope stability analysis, Eng. Optimiz., 35, 51-65, 2003.

Chen, Z.: Stability analysis of soil slopes: theories, methods and programs, Water Power Press, Beijing, 2003 (in Chinese).

Cheng, Y. M.: Locations of Critical Failure Surface and some Further Studies on Slope Stability Analysis, Comput. Geotechn., 30, 255-267, 2003.

Cheng, Y. M. and Lau, C. K.: Soil Slope stability analysis and stabilization - new methods and insights, 2nd Edn., Spon Press, 2014.

Cheng, Y. M. and Li, L.: Particle swarm optimization algorithm for the location of the critical non-circular failure surface in two dimensional slope stability analysis, Comput. Geotechn., 4, 92103, 2007.

Cheng, Y. M. and Zhu, L. J.: Unified Formulation for Two Dimensional Slope Stability Analysis and Limitations in Factor of Safety Determination, Soil. Found., 44, 121-128, 2004.

Cheng, Y. M., Lansivaara, T., and Wei, W. B.: Two-dimensional Slope Stability Analysis by Limit Equilibrium and Strength Reduction Methods, Comput. Geotechn., 34, 137-150, 2007a.
Cheng, Y. M., Li L., and Chi, S. C.: Studies on six heuristic global optimization methods in the location of critical slip surface for soil slopes, Comput. Geotechn., 34, 462-484, 2007 b.

Cheng, Y. M., Li, L., Lansivaara, T., Chi, S. C., and Sun, Y. J.: An Improved harmony search minimization algorithm using different slip surface generation methods for slope stability analysis, Eng. Optimiz., 40, 95-115, 2008a.

Cheng, Y. M., Li, L., Chi, S.C., and Wei, W. B.: Determination of the critical slip surface using artificial fish swarms algorithm, J. Geotech. Eng.-ASCE, 134, 244-251, 2008b.

Cheng, Y. M., Lansivaara T., and Siu, J.: Impact of Convergence on Slope Stability Analysis and Design, Comput. Geotech., 35 , 105-115, 2008c

Ching, J., Phoon, K. K., and Hu, Y. G.: Efficient evaluation of reliability for slopes with circular slip surfaces using importance sampling, J. Geotech. Eng.-ASCE, 135, 768-777, 2009.

Cho, S. E.: Probabilistic stability analyses of slopes using the ANNbased response surface, Comput. Geotechn., 36, 787-797, 2009.

Chowdhury, R. N. and Xu, D. W.: Geotechnical system reliability of slopes, Reliab. Eng. Syst. Safe., 47, 141-151, 1995.

Chowdhury, R. N., Tang, W. H., and Sidi, I.: Reliability model of progressive failure of slopes, Geotechnique, 37, 467-81, 1987.

Christian, J. T., Ladd, C. C., and Baecher, G. B.: Reliability applied to slope stability analysis, J. Geotech. Engin.-ASCE, 120, 21802207, 1994.

Duncan, J. M.: Factors of safety and reliability in geotechnical engineering, J. Geotech. Geoenviron., 126, 307-316, 2000.

EI-Ramly, H., Morgenstern, N. R., and Cruden, D. M.: Probabilistic slope stability analysis for practice, Can. Geotech. J., 39, 665683, 2002.

Geem, Z. W., Kim, J. H., and Loganathan, G. V.: A new heuristic optimization algorithm: harmony search, Simulation, 76, 60-68, 2001.

Geotechnical Engineering Office: Highway slope manual, Hong Kong SAR Government, Hong Kong, 2000.

Goh, A. T. C.: Genetic algorithm search for critical slip surface in multiple-wedge stability analysis, Can. Geotech. J., 36, 382-359, 1999.

Greco, V. R.: Efficient Monte Carlo technique for locating critical slip surface, J. Geotech. Eng.-ASCE, 122, 517-525, 1996.

Griffiths, D. V. and Fenton, G. A.: Probabilistic slope stability analysis by finite elements, J. Geotech. Eng.-ASCE, 130, 507-518, 2004.

Griffiths, D. V., Huang, J., and Fenton, G. A.: Influence of spatial variability on slope reliability using 2-D random fields, J. Geotech. Eng.-ASCE, 135, 1367-1378, 2009.

Griffiths, D. V., Huang, J., and Fenton, G. A.: Probabilistic infinite slope analysis, Comput. Geotechn., 38, 577-584, 2011.

Hasofer, A. A. and Lind, A. M.: Exact and invariant second moment code format, J. Eng. Mechan. Div.-ASCE, 100, 111-121, 1974.

Hassan, A. M. and Wolff, T. F.: Search algorithm for minimum reliability index of earth slopes, J. Geotech. Eng.-ASCE, 125, 301308, 1999.

Hong, H. P. and Roh, G.: Reliability evaluation of earth slopes, J. Geotech. Eng.-ASCE, 134, 1700-1705, 2008.

Honjo, Y. and Kuroda, K. A.: New look at fluctuating geotechnical data for reliability design, Soil. Found., 31, 110-120, 1991.

Kang, F., Han, S. X., Salgado, R., and Li, J. J.: System probabilistic stability analysis of soil slopes using Gaussian process regression 
with Latin hypercube sampling, Comput. Geotechn. , 63, 13-25, 2015.

Lee, K. S. and Geem, Z. W.: A new meta-heuristic algorithm for continuous engineering optimization: harmony search theory and practice, Comput. Method. Appl. Mechan. Eng., 194, 39023933, 2005.

Li, K. S. and Lumb, P.: Probabilistic design of slopes, Can. Geotech. J., 24, 520-535, 1987.

Li, L. and Chu, X. S.: An improved Particle Swarm optimization Algorithm with Harmony Strategy for the Location of Critical Slip Surface of Slopes, China Oc. Eng., 25, 357-364, 2011.

Li, L., Yu, G. M., Chen, Z., and Chu, X. S.: Discontinuous flying particle swarm optimization algorithm and its application to slope stability analysis, J. Cent. South Univ. T., 17, 852-856, 2010.

Liu, X., Griffiths, D. V., and Tang, H. M.: Comparative Study of System Reliability Analysis Methods for Soil Slope Stability, Engineering Geology for Society and Territory, edited by: Lollino, G., Giordan, D., Crosta, G. B., Corominas, J., Azzam, R., Wasowski, J., Sciarra, N., Springer International Publishing Switzerland, 2, 1363-1366, 2015.

Low, B. K. and Tang, W. H.: Efficient spreadsheet algorithm for first-order reliability method, J. Eng. Mechan.-ASCE, 133, 1378-1387, 2007.
Low, B. K., Gilbert, R. B., and Wright, S. G.: Slope reliability analysis using generalized method of slices, J. Geotech. Eng.-ASCE, 124, 350-362, 1998.

Malkawi, A. I. H., Hassan W. F., and Abdulla, F. A.: Uncertainty and reliability analysis applied to slope stability, Struct. Saf., 22,161187, $(2000$.

Oka, Y. and Wu, T. H.: System reliability of slope stability, J. Geotech. Eng.-ASCE, 116, 1185-1189, 1990.

$\mathrm{Xu}, \mathrm{B}$. and Low, B. K.: Probabilistic stability analyses of embankments based on finite-element method, J. Geotech. Eng.-ASCE, 132, 1444-1454, 2006.

Xue, J. F. and Gavin, K.: Simultaneous Determination of Critical Slip Surface and Reliability Index for Slopes, J. Geotech. Eng.ASCE, 133, 878-886, 2007.

Yi, P., Wei, K. T., Kong, X. J., and Zhu, Z.: Cumulative PSOKriging model for slope reliability analysis, Probabilist. Eng. Mech., 39, 39-45, 2015.

Zhang, J., Zhang, L. M., and Tang, H.: New methods for system reliability analysis of soil slopes, Can. Geotech. J., 48, 11381148, 2011.

Zhang, J., Huang, H. W., and Phoon, K. K.: Application of the Kriging-Based Response Surface Method to the System Reliability of Soil Slopes, J. Geotech. Eng.-ASCE, 139, 651-655, 2013.

Zolfaghari, A. R., Heath, A. C., and McCombie, P. F.: Simple genetic algorithm search for critical non-circular failure surface in slope stability analysis, Comput. Geotechn., 32, 139-152, 2005. 